\title{
Prática pedagógica integrada de alfabetização matemática e literatura
} infantil

\author{
Fabio Colins*, Patrícia Pena Moraes**, Arthur Gonçalves Machado Júnior ${ }^{\star \star \star}$
}

\section{Resumo}

Este artigo tem como objetivos apresentar, descrever e discutir o ensino integrado de alfabetização matemática e linguística por meio da literatura infantil, no que concerne, especificamente, o ensino de geometria. As propostas didáticas apresentadas nesta pesquisa abordam o ensino de geometria (espaço e forma), especificamente as habilidades relacionadas a localização e movimentação no espaço, reconhecimento, composição e decomposição de figuras planas e seus elementos (aresta, vértice, lado, etc.), a partir da leitura de dois textos de literatura infantil. A prática docente deu-se por meio de duas sequências de atividades, construídas com o propósito de desenvolver um ensino integrado de alfabetização matemática e alfabetização linguística em uma turma multisseriada, composta por alunos de $1^{\circ}, 2^{\circ}$ e $3^{\circ}$ anos do ensino fundamental. Nesta pesquisa, percebemos que é possível trabalhar a disciplina matemática de maneira contextualizada e integrada com a língua portuguesa por meio da literatura infantil.

Palavras-chave: Alfabetização matemática. Literatura infantil. Prática pedagógica integrada.

Doutorando em Educação em Ciências e Matemáticas na Universidade Federal do Pará (UFPA). Professor de Matemática - Secretaria de Estado de Educação do Pará. Instituto de Educação Matemática e Científica da UFPA. E-mail: formador.ufpa@gmail.com

* Mestranda em Docência em Educação em Ciências e Matemática na UFPA. Professora dos anos iniciais do ensino fundamental e da educação especial - Secretaria Municipal de São Francisco do Pará. Instituto de Educação Matemática e Científica da UFPA. E-mail: teacherpatriciamoraes@gmail.com

*** Professor do Instituto de Educação Matemática e Científica da UFPA. Professor do Programa de Pós-Graduação em Docência em Educação em Ciências e Matemática da UFPA. Instituto de Educação Matemática e Científica da UFPA. E-mail: agmj@ufpa.br 


\section{Introdução}

Por muito tempo se falou em alfabetização apenas como aprender a ler ou a escrever em língua materna, e pouco se dava importância à alfabetização matemática, mas essa área do conhecimento tem sua linguagem específica. Portanto, o processo de alfabetização das crianças do primeiro ciclo do ensino fundamental ( $1^{\circ}$ ao $3^{\circ}$ ano) precisa perpassar por um processo interdisciplinar. Nesse sentido, partimos do pressuposto de que o trabalho integrando a matemática e a literatura infantil já seria um bom começo. Nesse sentido, as crianças, quando inseridas no processo de alfabetização matemática, precisam ser levadas a mobilizar saberes matemáticos relacionados a construção das noções de número e suas funções nas práticas sociais, operações com esses números, leitura de mapas, gráficos e tabelas e movimentação e localização no espaço.

Nesse sentido, o professor alfabetizador precisa propor uma alfabetização matemática integrada à alfabetização em língua materna por meio de práticas de leitura. Mas como é possível desenvolver um trabalho de alfabetização matemática e linguística de forma integrada? Partindo desse questionamento, o presente artigo tem como objetivos apresentar, descrever e discutir as práticas de alfabetização matemática e linguística por meio do letramento literário, no que concerne, especificamente, ao eixo espaço e forma: a localização e a movimentação do espaço (considerando mais de um ponto de referência), reconhecimento de figuras planas e seus elementos geométricos, etc. Todas essas habilidades do campo geométrico precisam estar conectadas ao processo de leitura de diversos gêneros textuais. Para isso, saber ler e escrever não basta, as crianças precisam saber fazer uso dessas habilidades para responder às exigências de leitura e de escrita que são feitas pela sociedade diariamente. Mas o que consideramos como alfabetização matemática na perspectiva do letramento literário?

\section{Alfabetização matemática na perspectiva do letramento literário}

O que consideramos como alfabetização matemática na perspectiva do letramento literário não é somente utilizar textos para ensinar nas aulas de matemática, mas aprender matemática para ler os textos de literatura. Para isso, faz-se necessário que 
o professor alfabetizador, durante todo o processo de alfabetização matemática, possibilite aos seus alunos um trabalho integrado entre práticas de leitura e conteúdos matemáticos: números e operações, grandezas e medidas, geometria e tratamento da informação. Esses são, segundo os Parâmetros Curriculares Nacionais (PCNs), os quatro grandes blocos de conteúdos que constituem as habilidades necessárias no processo de alfabetização matemática. No que concerne, especificamente, ao bloco de conteúdos sobre geometria, a criança em processo de alfabetização matemática precisa, por meio de atividades integradas de matemática e literatura infantil, mobilizar saberes matemáticos relacionados a composição e decomposição de figuras geométricas planas, leitura de informações em mapas, construção e representação de figuras geométricas não planas, movimentação e localização no espaço utilizando um ou mais pontos de referência, criação de itinerários, etc. (BRASIL, 1997).

Esses saberes matemáticos relacionados à alfabetização matemática precisam ser trabalhados de tal forma que os professores alfabetizadores criem rotinas de leitura nas aulas, com leitura individual, compartilhada, silenciosa, desafiadora, etc. Além disso, devem explorar, nos textos, juntamente com as ideias sobre o conteúdo matemático, novas informações, aprendizagens e conhecimentos de como organizar o saber matemático.

Para Fonseca (2014), a relação entre a leitura e a escrita em matemática apresenta relevância por sua inferência nas práticas de leituras escolares. De fato, há textos que circulam pela sociedade e apresentam uma linguagem matemática, mas essa linguagem só ajuda a constituir sentido para aqueles que conseguirem mobilizar os conhecimentos matemáticos durante a leitura, e são estes mesmos conhecimentos que podem auxiliar na resolução de problemas da área da matemática. No entanto, o trabalho integrando alfabetização linguística e matemática pode ser realizado por meio da literatura infantil.

A alfabetização matemática por meio da literatura infantil pode ser integrada à alfabetização em língua materna, mas requer do professor alfabetizador um planejamento bem elaborado. Além disso, é necessário que o educador também aprecie poemas, selecione textos de qualidade (textos adequados à idade das crianças), planeje e organize espaços e situações que favoreçam uma alfabetização na perspectiva do letramento literário. Para Faria (2012), é de grande importância o professor ter uma formação literária básica para saber analisar os livros infantis, selecionar o que pode interessar às crianças num momento dado e decidir sobre os elementos 
literários que sejam úteis para ampliar o conhecimento do leitor, mobilizando saberes de outras áreas, por exemplo, da matemática. Nesse sentido, a literatura infantil pode ser uma estratégia para garantir um ensino de matemática que faça sentido para quem está aprendendo e que dê significado aos conteúdos matemáticos ensinados. Para Lopes (2009, p. 66):

A leitura de textos que tenham como objeto conceitos e procedimentos matemáticos, história da matemática ou reflexões sobre a matemática, seus problemas, seus métodos, seus desafios pode, porém, muito mais do que orientar a execução de determinada técnica, agregar elementos que não só favoreçam a constituição de significados dos conteúdos matemáticos mas também colaborem para a produção de sentidos da própria matemática e de sua aprendizagem pelo aluno.

Além de dar sentido e significado ao que se aprende e ao que se ensina, a literatura infantil possibilita um contexto em que o aluno se expressa de maneira natural e informal, por meio de uma leitura lúdica e dinâmica. Porém, proporcionar aos alunos a alfabetização matemática e linguística de maneira integrada é um dos grandes desafios enfrentados pelos professores que ensinam matemática nos anos iniciais do ensino fundamental.

\section{Encaminhamentos metodológicos}

Esta investigação é resultante de uma prática de sala de aula de um professor alfabetizador que leciona numa turma multisseriada de uma escola da rede municipal de ensino situada no município de Muaná, Marajó, Pará, Brasil, composta por alunos de $1^{\circ}, 2^{\circ}$ e $3^{\circ}$ anos do ensino fundamental. A instituição escolar fica situada numa comunidade ribeirinha. Nesse espaço geográfico, as ruas são formadas por rios, como mostra um desenho construído por um dos alunos, apresentado a seguir. As informações foram organizadas a partir do planejamento do docente e seu relato de experiência. Por isso, durante a discussão, há trechos da fala do professor e imagens (autorizadas para estudo e publicação) dos resultados das aulas.

A prática discutida neste artigo compreende a organização e o desenvolvimento de duas sequências de atividades a partir dos seguintes livros de literatura infantil: Chapeuzinho Vermelho, uma aventura borbulhante e Eu, um quadrado? A primeira história é uma adaptação do conto "Chapeuzinho Vermelho". É a história de um menino, uma avó, um grande Lobo Mau e um garrafão de refrigerante delicioso. 
Lynn e David Roberts, os autores da obra, deram um toque de imaginação à história clássica e criaram uma imperdível e borbulhante aventura. A segunda, conta a história de um quadrado que vivia se interrogando sobre quem era realmente. Até um dia ouvir alguém dizer: "Olhe, um quadrado!".

Com a primeira história (Chapeuzinho Vermelho, uma aventura borbulhante), foram abordados com os alunos conhecimentos sobre movimentação e localização no plano, a partir de mais de um referencial, construção e leitura de mapas, lateralidade e outros conhecimentos relacionados ao tema espaço e forma. Com o segundo livro ( $E u$, um quadrado?), tratou-se sobre conhecimentos matemáticos acerca da geometria plana, reconhecimento de figuras planas, definições, regularidades, características das principais figuras planas, etc. Para isso, foram construídas e aplicadas duas sequências de atividades.

A primeira sequência de atividades teve como base o livro "Chapeuzinho Vermelho, uma aventura borbulhante". Ela foi desenvolvida em 20 horas de aula e tinha como objetivos: identificar lugares usando mais de um ponto de referência, localizar-se e movimentar-se nos pontos de referência e desenvolver as noções de referência espacial (lateralidade). O conteúdo abordado foi lateralidade, construção e leitura de mapas e de itinerário. Os materiais básicos necessários para o desenvolvimento dessa sequência de atividade foram: cartolinas, canetas coloridas, régua, lápis de grafite, quadro branco, pincel piloto, papel A4 e lápis de cor.

A atividade deu-se primeiramente pela leitura e exploração da história. Os seguintes questionamentos nortearam a leitura: sobre o que o livro trata? Qual foi o caminho percorrido por Chapeuzinho Vermelho até a casa da vovozinha? Ele poderia fazer outro percurso? Qual? Em seguida, os alunos receberam uma folha de papel A4 e foram desafiados a desenharem o caminho que chapeuzinho fez para chegar até a casa da vovozinha, indicando pontos de referência. Depois, as crianças aproveitaram para desenhar o percurso de sua casa até a escola, também indicando pontos de referência. Na sequência, os alunos trocaram os mapas para tentarem ler o caminho traçado por cada colega. Por fim, a história foi lida novamente e os alunos foram indicando, em seus mapas, o percurso do Chapeuzinho Vermelho. Ao finalizar as sequências de atividades, foram recolhidos os registros dos alunos para discutir sobre os conhecimentos matemáticos e linguísticos mobilizados durante o desenvolvimento das atividades em sala de aula. 
$\mathrm{Na}$ segunda sequência de atividades, o trabalho foi realizado com o livro " $E u$, um quadrado?", em 16 horas de aula, com os objetivos de identificar os elementos essenciais para construção de quadrados e retângulos, reconhecer elementos que as formas geométricas possuem, tais como faces, arestas e vértices, e ampliar o conhecimento sobre as figuras geométricas planas por meio de suas principais características (número de lados, ângulos e vértices). Os conteúdos matemáticos dessa sequência foram: figuras planas (quadriláteros). Os materiais básicos necessários para a realização das atividades foram: cartolinas, canetas coloridas, régua, lápis de grafite, dicionários, quadro branco, pincel piloto, pincel para quadro branco e livros didáticos. A atividade foi organizada em momentos distintos de aprendizagem.

No primeiro momento de aprendizagem, foram realizadas a apresentação e a leitura do livro "Eu, um quadrado?". Exploraram-se bastante as figuras, o título da história e as falas dos personagens. Inicialmente, fez-se um trabalho de pré-leitura, uma forma de antecipação do conteúdo da história. Em seguida, a turma foi dividida em grupos, com o objetivo de indicar as características do quadrado a partir da história: número de lados, ângulos, vértices, etc. Os alunos utilizaram dicionários e o livro didático de matemática para compreender alguns conceitos tratados na história. Depois, sob a orientação do professor, desenharam, em cartolina, quadriláteros e triângulos e explicaram suas características e diferenças. Além disso, fizeram pesquisas nos livros didáticos sobre a classificação das figuras geométricas de acordo com o número de lados e os ângulos. Por fim, cada grupo apresentou seus desenhos, expondo suas ideias sobre os conceitos geométricos estudados. Ao final da atividade, foram expostas as produções no mural da escola, para que todos pudessem visualizá-las.

\section{Os resultados}

Na primeira atividade, o professor realizou a leitura do livro Chapeuzinho Vermelho, uma aventura borbulhante para os alunos. Após ouvir a história, eles desenharam o trajeto que o garoto da história tinha feito, desde a casa dele até a casa de sua avó. Com isso, foram orientados a prestar bastante atenção nos detalhes da história e a fazer anotações dos locais por onde Chapeuzinho Vermelho tinha passado. Todos os alunos ficaram concentrados nessa atividade. Na Figura 1, apresenta-se uma produção de um aluno nessa atividade: 
Figura 1 - Produção de aluno

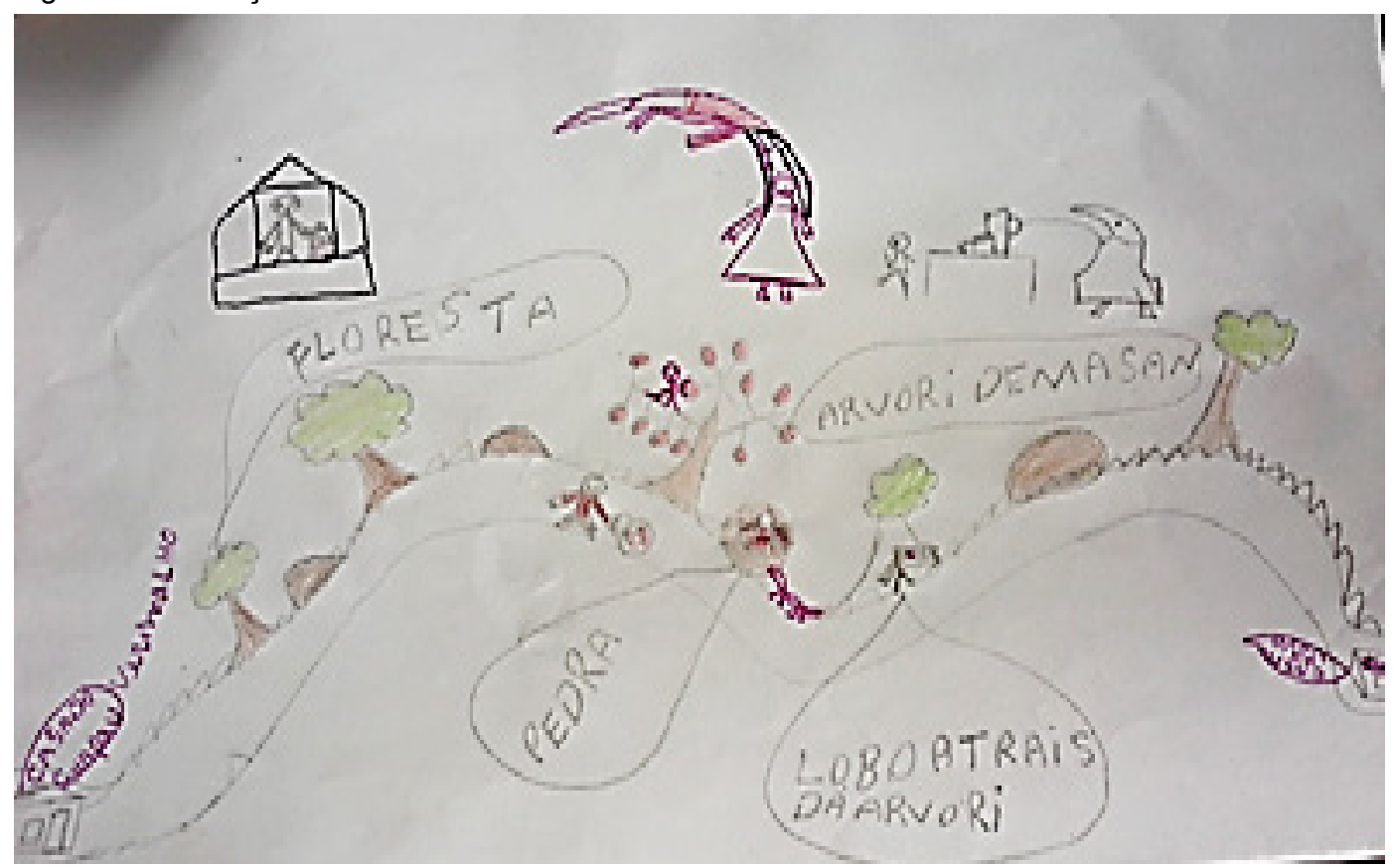

Fonte: autores.

Nessa atividade, percebe-se que o trabalho com a leitura do texto literário possibilitou que os alunos mobilizassem conhecimentos matemáticos relacionados com a geometria, especificamente, sobre movimentação e localização no espaço. No desenho (Figura 1), percebe-se que o aluno representa informalmente a posição de pessoas e objetos e, ainda, dimensiona espaços por meio do desenho do trajeto feito pelo personagem da história. Com isso, ele desenvolveu noções de tamanho, lateralidade, localização, direcionamento, sentido e vistas. Ele conseguiu identificar e descrever a movimentação de pessoas e objetos de mais de um referencial, além de identificar mudanças de direção e sentido. Sobre esse tipo de trabalho, Fonseca (2009, p. 49) afirma que:

[...] o ensino de geometria deve contribuir para ampliar e sistematizar o conhecimento espontâneo que a criança tem do espaço em que vive. Perceber e organizar o mundo físico leva à representação e à modificação desse espaço, que é o que fazem, por exemplo, os desenhistas, os topógrafos, os engenheiros e os arquitetos. 
Portanto, os alunos, a partir da leitura, conseguiram indicar os pontos de referência que ouviram na história. Nesse caso, percebe-se que a noção de espaço foi ampliada, pois eles passaram de uma geometria topológica (geometria do espaço vivido) para uma geometria projetiva (geometria por meio de perspectivas). Além dos conhecimentos matemáticos mobilizados pela atividade, as práticas de ler e escrever nas aulas de matemática contribuem para a alfabetização linguística das crianças e ampliam o raciocínio lógico matemático dos alunos. Essa prática poderia estar presente em todas as salas de aula de alfabetização, independentemente da disciplina.

Nesse sentido, destaca-se o relato de experiência do professor alfabetizador da turma:

Eu nunca tinha ministrado uma aula dessas. Primeiro fiquei pensando sobre o que ensinar de matemática tomando esse livro como referência, já que ele, a priori, não traz nada de conteúdo matemático, mas quando parei para refletir melhor, e depois da conversa que tive com o meu professor formador, percebi que era possível sim. Os alunos estranharam um pouco, mas depois eles entenderam e acharam fácil a aula de geometria. Gostaram principalmente porque envolvia a realidade deles, sua comunidade.

$\mathrm{Na}$ fala do alfabetizador, percebe-se que essa atividade possibilitou também conduzir os alunos ao reconhecimento de si próprios e da realidade que os circunda. A convivência de forma lúdica e prazerosa com textos literários favorece a formação do espírito crítico do leitor, aguça o seu desejo de transformar a realidade, inserindo outras formas de ser e estar no mundo. Portanto, a atividade de integração da língua portuguesa e da matemática rompeu com uma prática que se manifesta em muitas aulas de geometria, ignorar os sentidos, o próprio corpo e as experiências dos estudantes em relação ao espaço, reduzindo o estudo da geometria a figuras planas. Destaca-se a importância de explorar os conhecimentos sobre ocupação do espaço que as crianças trazem, o vocabulário que usam, os esquemas de representação que possuem e as noções de lateralidade que elas já têm. Esses são cuidados iniciais muito importantes, porque muitos alunos não passaram por um processo de alfabetização matemática.

Para continuar ampliando os conhecimentos matemáticos sobre geometria, o professor solicitou, logo em seguida, que os alunos construíssem um mapa, indicando o trajeto que percorrem de suas casas até a escola, sempre tendo o cuidado de indicar pontos de referência para facilitar a leitura da imagem (Figura 2). Essa 
tarefa tinha como objetivo ampliar o conhecimento dos alunos sobre a construção de itinerários.

Figura 2 - Produção de aluno

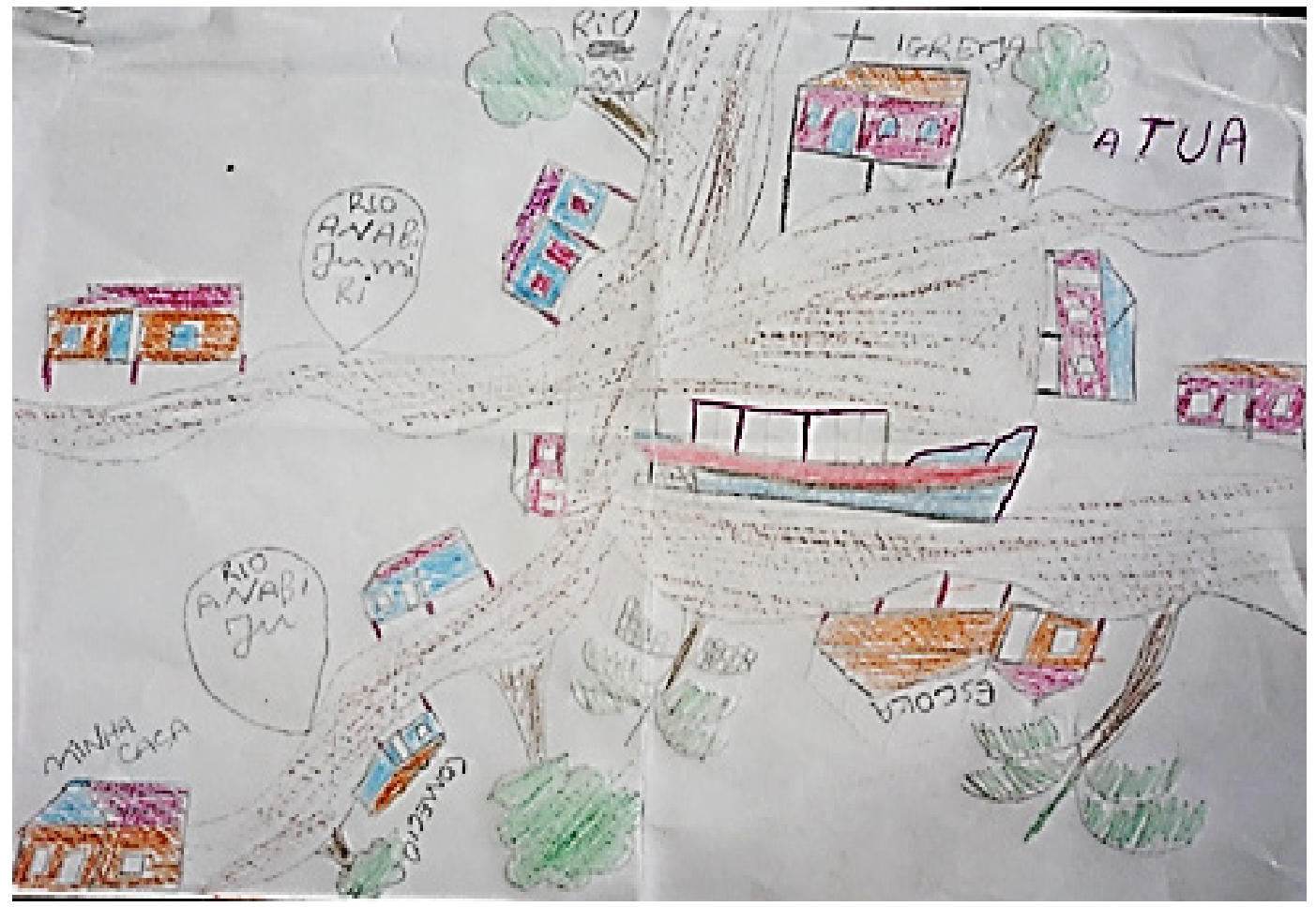

Fonte: autores.

Essa atividade possibilitou aos alunos reconhecer seu próprio corpo como referencial de localização e deslocamento no espaço, observar, experimentar e representar posições de objetos em diferentes perspectivas, considerando diferentes pontos de vista e utilizando diferentes linguagens. Nessa tarefa, os alunos puderam expor sua noção de espaço em relação ao local em que moram, recorrendo ao uso de vários pontos de referência.

Segundo Fonseca (2009), as crianças, desde o seu nascimento, procuram conhecer e explorar o espaço em que vivem, dirigindo suas ações e sua atenção nesse sentido. Elas vão explorando esse mundo geométrico a partir de suas necessidades ou de sua curiosidade, construindo, assim, certa competência geométrica. 
A imagem permite observar que o aluno usa vários pontos de referência em seu percurso - rio, barco, comércio, igreja, casas, a própria casa, árvores e a escola -, para mostrar sua perspectiva do ambiente com o qual convive diariamente. De um modo geral, os estudantes expressaram, por meio de seus desenhos, as experiências diversificadas que possuem em relação à região em que vivem e aos locais em que podem ter vivido ou dos quais podem ter ouvido falar. Fica clara a relação que eles estabelecem com os diferentes espaços mostrados nos mapas.

Destaca-se outro relato do professor alfabetizador sobre essa aula:

Nessa aula de construção de itinerários os alunos puderam vivenciar seu cotidiano e pensar sobre a matemática na nossa vida. E a minha aula ficou mais interessante. Percebi que a escolha do livro de literatura foi importante para o meu planejamento e para a aprendizagem dos alunos. É que eles aprenderam a linguagem da geometria.

De acordo com o relato do professor, essa atividade mobilizou conhecimentos matemáticos extremamente importantes para a construção e ampliação do senso espacial dos alunos, não apenas pelo fato de utilizarem o vocabulário próprio da geometria, mas, também, no que diz respeito à construção de um vocabulário autônomo e à diversificado para indicar a localização e a movimentação de objetos e pessoas num determinado espaço, seja ele vivido ou imaginado. É nessa perspectiva que Fonseca (2009, p. 72) afirma que "[...] as experiências, o conhecimento, o interesse e as necessidades dos alunos devem ser considerados pelo professor ao decidir o percurso que fará com eles na abordagem da geometria".

A outra atividade matemática envolvendo a leitura de texto literário, desenvolvida a partir da obra "Eu, um quadrado?", tinha o objetivo de abordar elementos da geometria euclidiana (a geometria de figuras e formas geométricas). Como a história tratava de uma figura geométrica que tinha uma grande dúvida sobre o que ela era (quadrado, retângulo, triângulo, trapézio, etc.), os alunos foram orientados a observarem e anotarem as características do quadrilátero da história e, depois, foram desafiados a escrever um argumento para convencer os colegas de que o quadrilátero da história era um quadrado. Um grupo de alunos escreveu o argumento apresentado na Figura 3. 
Figura 3 - Produção dos alunos

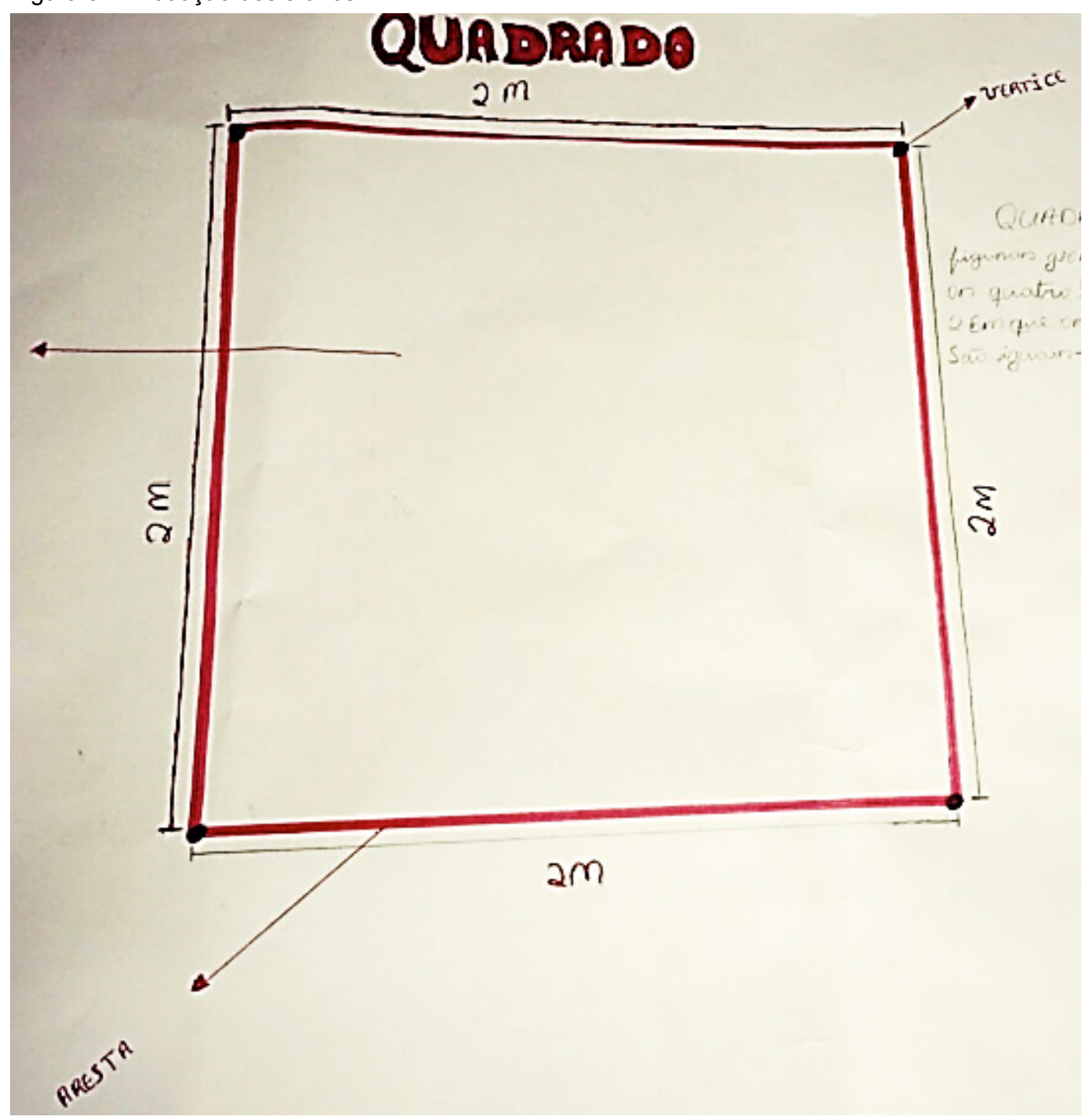

Fonte: autores.

Além de desenhar a figura com as medidas dos lados iguais (2 metros), os alunos explicaram que se tratava de um quadrado porque: “[...] é uma figura geométrica que tem os quatro lados e os quatro ângulos iguais. E o dado tem seis iguais”. Nessa atividade, os alunos puderam desenvolver e ampliar conhecimentos geométricos acerca da percepção das semelhanças e diferenças entre figuras geométricas, por 
meio de elementos da geometria euclidiana (medida dos lados, medida dos ângulos, número de lados, vértices, etc.). Essa tarefa foi avaliada pelo professor alfabetizador como complexa, conforme o seguinte relato:

Essa história foi mais difícil para os alunos porque falava de assuntos "pesados" da geometria: vértices, arestas, lados e ângulos. Mas quando fomos lendo e entendendo a história as coisas foram ficando mais fáceis. Utilizamos para facilitar dicionário e o livro didático. Foi bom porque os alunos conheceram outros assuntos da geometria ao invés de saber só o nome das figuras.

Pelo relato do alfabetizador, nota-se que esse trabalho possibilitou que os alunos descrevessem, comparassem e classificassem as figuras planas (no caso da atividade, os quadriláteros) por características comuns, mesmo apresentadas em diferentes disposições, descrevendo também por meio da oralidade. Além disso, mobilizaram saberes matemáticos específicos do bloco de conteúdos da geometria. Outro exemplo é apresentado na Figura 4:

Figura 4 - Produção dos alunos

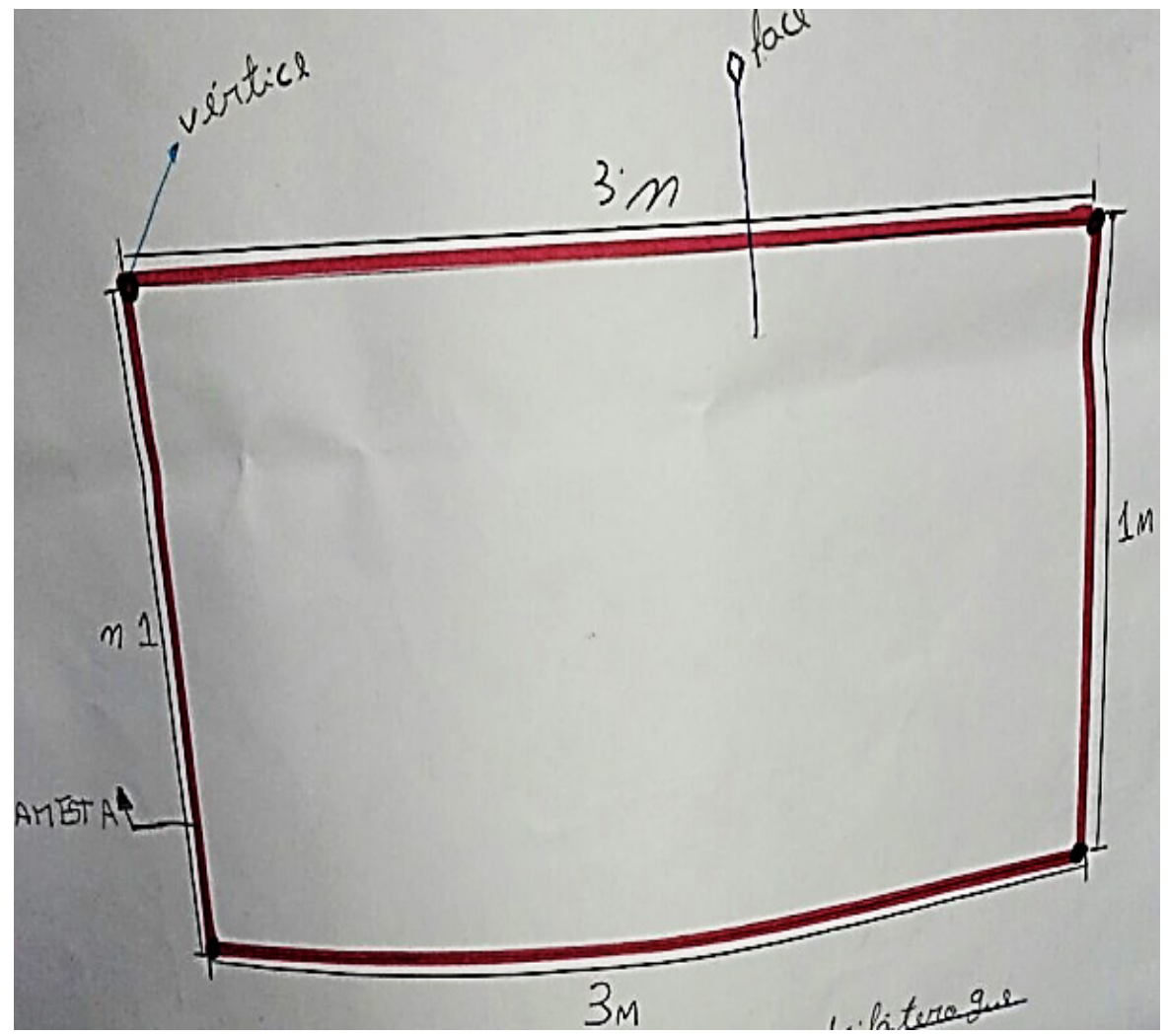

Fonte: autores 
Esse grupo de alunos recorreu a alguns elementos geométricos para justificar que o quadrilátero representado na figura era um retângulo. Face, vértice e aresta, mesmo que utilizados de forma equivocada, foram os elementos geométricos utilizados para tentar validar seus conhecimentos geométricos. O mais importante nessa atividade foi a construção da argumentação, utilizando a linguagem matemática por meio da leitura, da escrita e da oralidade. Ainda, as atividades de geometria foram apresentadas, de modo geral, por meio de desenhos construídos pelos alunos, e isso facilitou a compreensão dos conteúdos matemáticos. Porém, Fonseca (2009, p. 77) chama a atenção dos professores no que concerne às atividades matemáticas com desenho:

Não é, entretanto, a simples atividade de desenhar que vai desenvolver a capacidade de representar uma figura geométrica. Muitas vezes, propomos aos alunos atividades que envolvem desenhos sem nenhuma orientação no sentido de permitir que avancem ou ampliem suas possibilidades de representação.

Por isso, além das orientações dadas sobre o desenvolvimento e os objetivos das atividades, os alunos foram orientados a pesquisar, em dicionários e livros didáticos de matemática, sobre o significado de algumas palavras ou expressões referentes à geometria. Além disso, procurou-se identificar e considerar o significativo conhecimento que os alunos tinham sobre geometria, para, somente depois, propor as atividades discutidas.

\section{Considerações finais}

A construção desta pesquisa possibilitou apresentar, descrever e discutir a importância de promover, nas aulas de matemática, atividades centradas nas práticas de leitura e escrita, mostrando que é possível ensinar matemática e língua portuguesa por meio da literatura infantil. Nas atividades propostas, quando os alunos foram colocados diante de situações do seu cotidiano, ou seja, de tarefas que propositalmente traduzem situações do seu dia a dia para uma linguagem escolar, como desenhar o trajeto de casa até a escola, fomentou-se a participação na aula, a construção de novas habilidades e a ampliação de outras, possibilitando a alfabetização em língua materna e em matemática.

O estudo provocou uma reflexão acerca de um ensino de geometria que vá além de ensinar o nome das figuras geométricas. Mostrou que é preciso considerar o en- 
sino da geometria como uma construção humana e histórica, com sua linguagem própria e que também permeia a linguagem cotidiana ("aparar as arestas", "sair pela tangente", "pessoa quadrada”, etc.). Percebeu-se que, apesar de os alunos apresentarem muitas dificuldades em relação às práticas de leitura e escrita na escola, eles participam de diversos eventos de práticas sociais (fora da escola) de leitura e escrita, por isso a importância de considerar seus conhecimentos prévios no momento de planejar as aulas.

Sobre a prática do professor alfabetizador, conclui-se que, devido a uma formação fragmentada, a prática de sala de aula recai num ensino, também, fragmentado. Por isso existem dificuldades em trabalhar um ensino de matemática integrado ao ensino de língua portuguesa por meio da leitura de textos literários. Contudo, pode-se afirmar que uma prática pedagógica interdisciplinar é possível.

Portanto, todos os professores da educação básica devem fomentar a prática da leitura nas diversas disciplinas do currículo, promover um ensino que fortaleça o interesse cada vez maior pela leitura e, consequentemente, pela matemática, pois muito do fracasso dos estudantes nas aulas de matemática decorre de dificuldades na leitura e na escrita.

\section{Educational practice integrated mathematics literacy and children's literature}

\section{Abstract}

This paper aims to present, describe and discuss the integrated teaching math literacy and linguistic literacy through children's literature regarding specifically the teaching of geometry. Didactic proposals in this research approach the teaching of geometry (Space and Shape), specifically the skills related to the location and movement in space, recognition, composition and decomposition of plane figures and their elements (edge, vertex, side, etc.) from reading two Children's literature texts. The teaching practice was given by two sequences of activities built with the purpose of developing an integrated teaching math literacy and linguistic literacy in a multisseriate class composed of students of the $1^{\text {st }}, 2^{\text {nd }}$ and $3^{\text {rd }}$ year of elementary school. In this research we realized that you can work the mathematical discipline of contextualized and integrated way with the English language through children's literature.

Keywords: Numeracy. Children's literature. Integrated pedagogical practice. 


\section{Referências}

BRASIL. Secretaria de Educação Fundamental. Parâmetros Curriculares Nacionais: matemática. Brasília, DF: MEC/SEF, 1997.

FARIA, Maria Alice. Como usar a literatura infantil na sala de aula. 5. ed. São Paulo: Contexto, 2012.

FONSECA, Maria da Conceição Ferreira Reis. O ensino de geometria na escola fundamental: três questões para a formação do professor dos ciclos iniciais. Belo Horizonte: Autêntica, 2009.

FONSECA, Maria da Conceição Ferreira Reis. Alfabetização matemática. In: BRASIL. Ministério da Educação. Secretaria de Educação Básica. Pacto Nacional pela Alfabetização na Idade Certa: caderno de apresentação. Brasília, DF: MEC/SEB, 2014. p. 27-32.

LOPES, Celi Aparecida Espasandin. Escritas e leituras na educação matemática. Belo Horizonte: Autêntica, 2009. 